\title{
Farmers' perception and knowledge of climate change and their coping strategies to the related hazards: Case study from Adiha, central Tigray, Ethiopia
}

\author{
Dejene K. Mengistu*
}

Department of Dryland Crop and Horticultural Sciences, Mekelle University, Mekelle, Ethiopia.

*Corresponding Author: dejenekmh@yahoo.com; dejenekmh@gmail.com

Received 11 February 2011; revised 15 March 2011; accepted 30 March 2011.

\section{ABSTRACT}

Climate change adversely affects Ethiopian economy due to heavy dependence of the agricultural sector on rainfall. A decrease of rainfall and rise in temperature has been increasing the exposure of the country to frequent drought. The study was conducted in central Tigray, Adiha tabia, to examine the perception of farmers on trends of climate changes and existing coping strategies. Farmers' knowledge of various adaptation strategies, drought early warning system and weather forecasting were assessed using focus group discussion (FGD), which consisted of 144 systematically sampled respondents. Temperature is rising while precipitation is declining from time to time. Untimely rain and frequent drought are challenging crop production in the area. Drought is perceived, both by male and female respondents, as the primary climate related hazard which is occurring frequently and affecting their livelihood. Individual's vulnerability to this hazard varies based on their hazard coping capacity. Lack of modern early warning systems, inflexible cropping calendar and narrow choice of crop varieties should aggravates the vulnerability. Hence, improveing forecasting and dissemination of climate information, developing drought resistant varieties and promoting farm-level adaptation measures like use of irrigation technologies and adjusting planting dates should be prioritized to improve community resilience to climate change.

Keywords: Adiha; Knowledge and Perception; Climate Change; Vulnerability; Coping; Adaptation

\section{INTRODUCTION}

Climate variability has attracted much attention in recent decades, not only because of the globally unparalleled persistence of anomalously low rainfall, but also because of the low capacity of society and economical systems to cope with climate change related risks. As a result of this low capacity, extreme climate variability, such as drought, is frequently accompanied by ecological decline, decimation of livestock herds, widespread food scarcity, mass migration and great loss of human life [1]. Climate change with expected long term changes in rainfall patterns and shifting temperature zones are expected to have negative effects on agriculture [2]. Ethiopia's agriculture, which is the mainstay of the country's economy constituting more than half the nation's gross domestic product (GDP) and generates more than 85 percent of the foreign exchange earnings [3], is mainly rainfed and heavily depend on rainfall. When the rainfall fells, the GDP falls [4]. This dependence makes the country particularly vulnerable to the adverse impacts of climate change. Literatures showed that the scope (geographic coverage), frequency and magnitude of climatic changes and environmental degradation such as deforestation, and soil erosion have been increasing from time to time in Ethiopia [5]. The potential adverse effects of climate change on Ethiopia's agricultural sector are of a major concern because of this dependence [6].

According to the National Meteorological Agency, long-term climate change in Ethiopia is associated with changes in rainfall patterns and variability, and temperature, which could increase the country's frequency of both droughts and floods. These climatic hazards, particularly drought, are becoming the major forces challenging the livelihoods of most farmers. Thought the country's crop production and productivity seem in- 
creasing since 1980's [7], the problem of food insecurity at national level remains the concern because of severity of food production constraints in some regions, markets that do not function and vulnerability of farmers to the shocks.

The rural population, for whom agriculture is the primary source of food, direct and/or indirect employment and income, will be most affected due agriculture's vulnerability to climate changes. As the sector is the largest consumer of water resources, variability in water supply has a major influence on health and welfare of agriculture dependent poor [7]. Vulnerability analysis made across the different regions of Ethiopia by reference [8] indicated that the exposure, sensitivity and adaptive capacity of people vary from region to region. The same report indicated that Tigray is among the most vulnerable regions because of higher frequencies of drought and floods, lower access to technologies, fewer institutions dealing with climate related hazards, and lack of infrastructures. Vulnerability to climatic change is highly correlated with poverty and living status of farmers determines their vulnerability to and adaptation with climatic changes. An increase in the frequency of climate related hazards could lead households to lower expected income which in turn can cause to fall below poverty threshold level [9].

Adaptation to climatic changes requires a combination of various individual responses at the farm-level and assumes that farmers have access to alternative practices and technologies available in their area. But it mainly involves changes in agricultural management practices in response to changes in climate conditions for agrarian community [2]. Adaptation of people to different hazards vary from household to households and region to region based on existing support system to increase the resilience of affected individuals. The assessment was aimed to generate primary information from the farming communities of Adiha related to climate change. This report examined the perception of Adiha farmers on the trend of climate change and related anomalities, existing coping strategies in place. Knowledge of farmers on various adaptation strategies, drought early warning system and climate forecast methods was assessed using focus group discussion. It would also draw implications that would assist policy makers to decrease the vulnerability of rural farming communities to adverse impacts of climate change.

\section{METHODOLOGY}

\subsection{The Site}

This study focused on Adiha, which is located in central Tigray and characterized by fragile resource base and varying climate conditions. The area is characterized by erratic rainfall. The main rains occur from June-August and sometimes it starts in May and stops in September and the wettest month is July/August. Seven years rainfall data, measured at Adiha weather station, indicated that the mean annual rainfall is about $600 \mathrm{~mm}$ ranging from 436 - $700 \mathrm{~mm}$ [3]. Its maximum and minimum temperatures are $27^{\circ} \mathrm{C}$ and $18^{\circ} \mathrm{C}$, respectively.

According to Kola-Temben Bureau of Agriculture and Rural Development (Figure 1), Adiha is the largest tabia of the Woreda with 10,920 hectares land size. It has four kueshets (villages) with 1783 households engaged in rain-fed and irrigated agriculture. The total population of the tabia is 8494 (males 3910 and females 4584). The rain-fed farmers constitute 613 households and the irrigators are 1170 households. The landless households are 283 .

\subsection{Methods}

Respondents were systematically sampled from Adiha tabia populations across all of the kueshets. One hundred forty four (144) respondents were sampled from population of the tabia. Various factors including gender (male/ female headed farm households), age, access to irrigation water and land holding size were considered during sampling.

\subsubsection{Focus Group Discussion (FGD)}

Focus Group Discussion (FGD) was employed to generate information on the perception of the farmers on climate change, its related hazards, vulnerable groups of the community and existing coping strategies. Six FGDs, each consisting 24 participants, 12 male and 12 women, drawn from different kueshets, were held for climate related hazard identification and characterization, identification and prioritization of coping mechanisms, identification and ranking of vulnerable groups and climate and weather forecasting. Tools such as hazard identification and characterization, hazard behavior story telling (timeline), hazard ranking matrix, vulnerability group ranking and experiential stories telling on indigenous technologies and knowledge were used to acquire information on farmers' perception on climate change trends, existing hazards and their severity and vulnerable groups of the community. The different coping strategies used by the community were also identified and analyzed for their effectiveness. Effectiveness was rated as very satisfactory, satisfactory and not satisfactory and the rating number converted to percent to assess satisfaction level.

\subsubsection{Data Management and Analysis}

Information was recorded using worksheets prepared for each category of discussion. Data collected on each parameter was expressed as percent of respondents. 


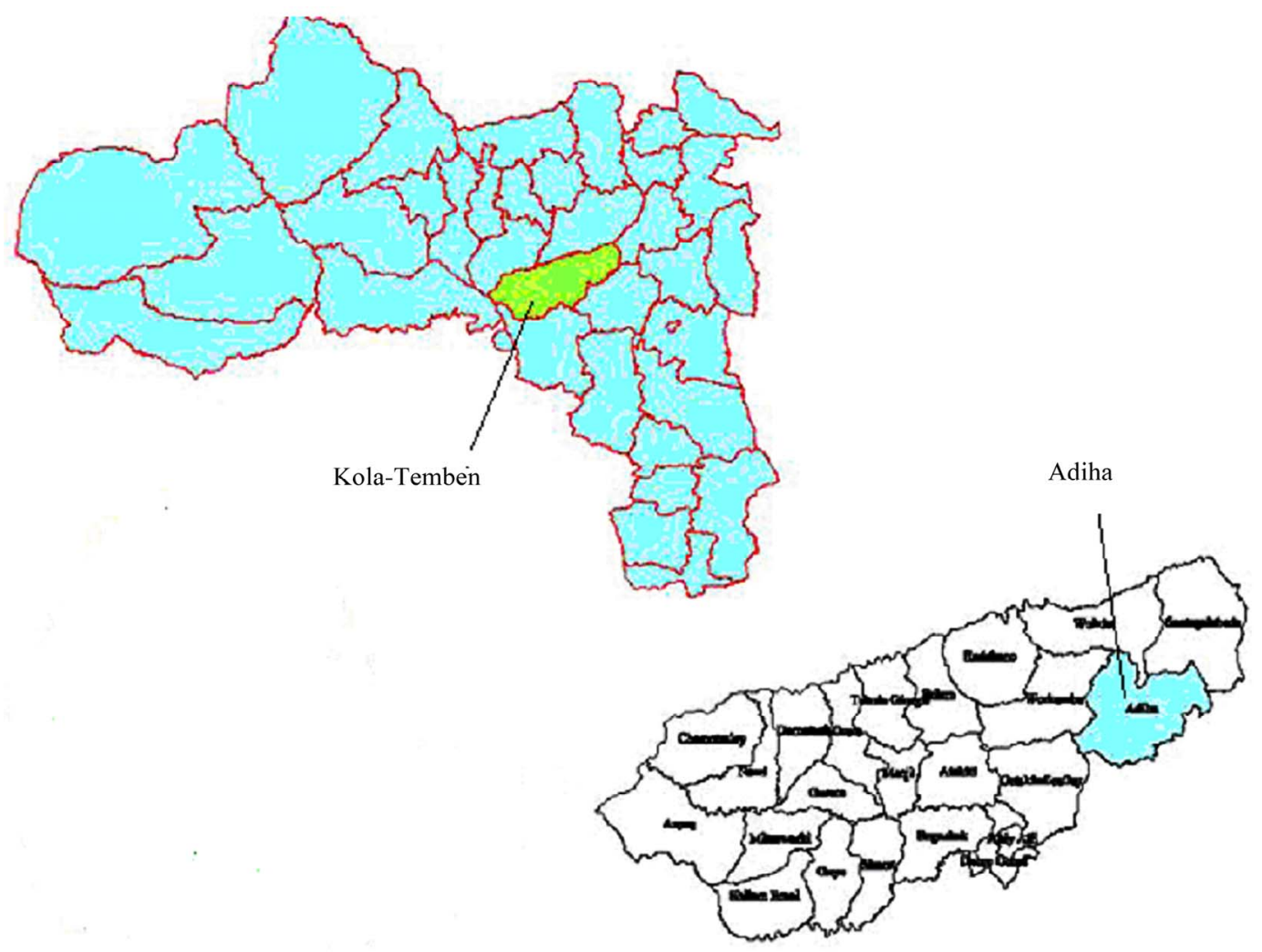

Figure 1. Location of Adiha tabia in the map of Tigray regional state.

Farmer's perceptions on changes in long-term temperature and precipitation as well as various coping strategies being used by farmers were analyzed and presented using simple descriptive statistics (tables and figures).

\section{RESULTS AND DISCUSSION}

\subsection{Farmers' Perception to Climate Change}

Change of climate was well perceived by communities of the study area as most of them have been observing changes in temperature, precipitation and timing of rainfall and related frequent drought (Figures 2 and 3). Perceptions on temperature and precipitation change were categorized into five and six groups, respectively. Almost all participants understood that the change of climatic conditions over the past 20 years was obvious. The result indicates that most farmers, about $75 \%$, perceive that the temperature of Adiha is increaseing in the last two decades (Figure 2) (temporal trend not indicated). Only $8 \%$ of them noticed the contrary, decrease in temperature. Very few of the respondents (less than $5 \%$ ) have not noticed any change in temperature.

On the other hand, 90\% of the respondents observed change in rainfall patterns in the last two decades in the area, and $70 \%$ have noticed a decrease in the amount of rainfall. About $20 \%$ of the informants noticed a change not in the total amount of rainfall but in the timing of the rains, with rains coming either earlier or later than expected. The over all perception is that Adiha and surrounding villages are getting drier (Figure 3 ) and there are pronounced changes in the timing of rains and frequency of droughts. It was indicated that drought occurs more frequent since 1992 than it was before.

It has been occurring more frequently to the level that two consecutive years remaining dry. The result is in agreement with the findings reported by references [10, 30,31] which indicated that African climate is highly variable and unpredictable and prone to extreme weather conditions, including droughts and floods.

\subsection{Climate Related Hazards and Community Vulnerability}

\subsubsection{Hazards Identification and Characterization}

The various hazards, directly or indirectly related to climate change, identified by the respondents were presented in Table 1. Both male and female respondents ranked drought (late onset and early cessation of rain) as the foremost climate related hazard and characterized it as the most disastrous in the area. Similar result was reported by reference [3]. Untimely rain and human diseases took the next rank by female and male 


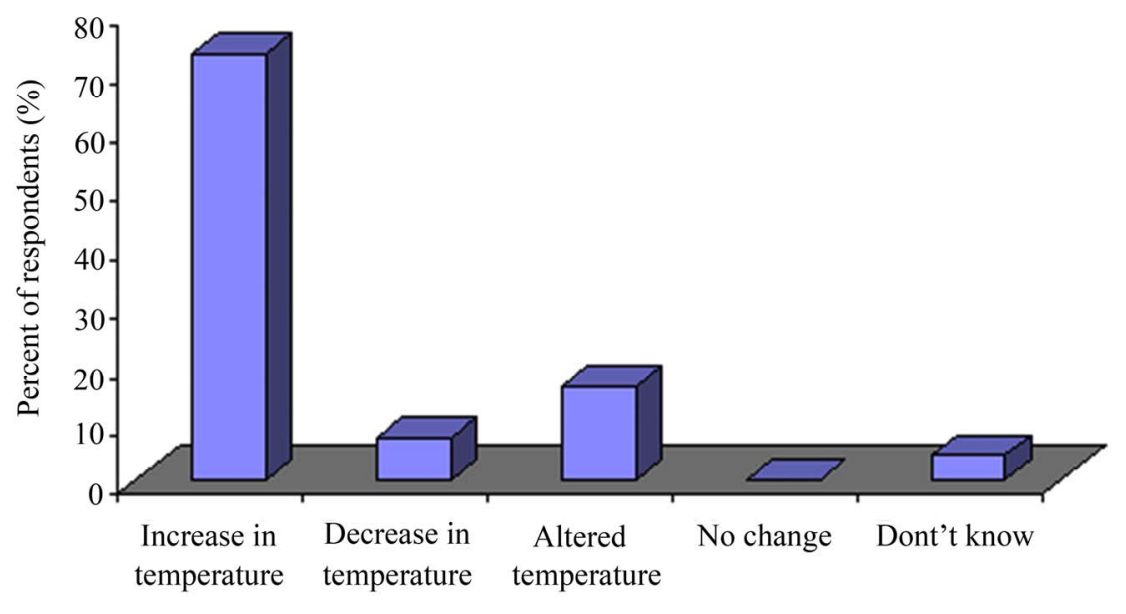

Farmers' perception

Figure 2. Farmers' perception on patterns of temperature changes in Adiha.

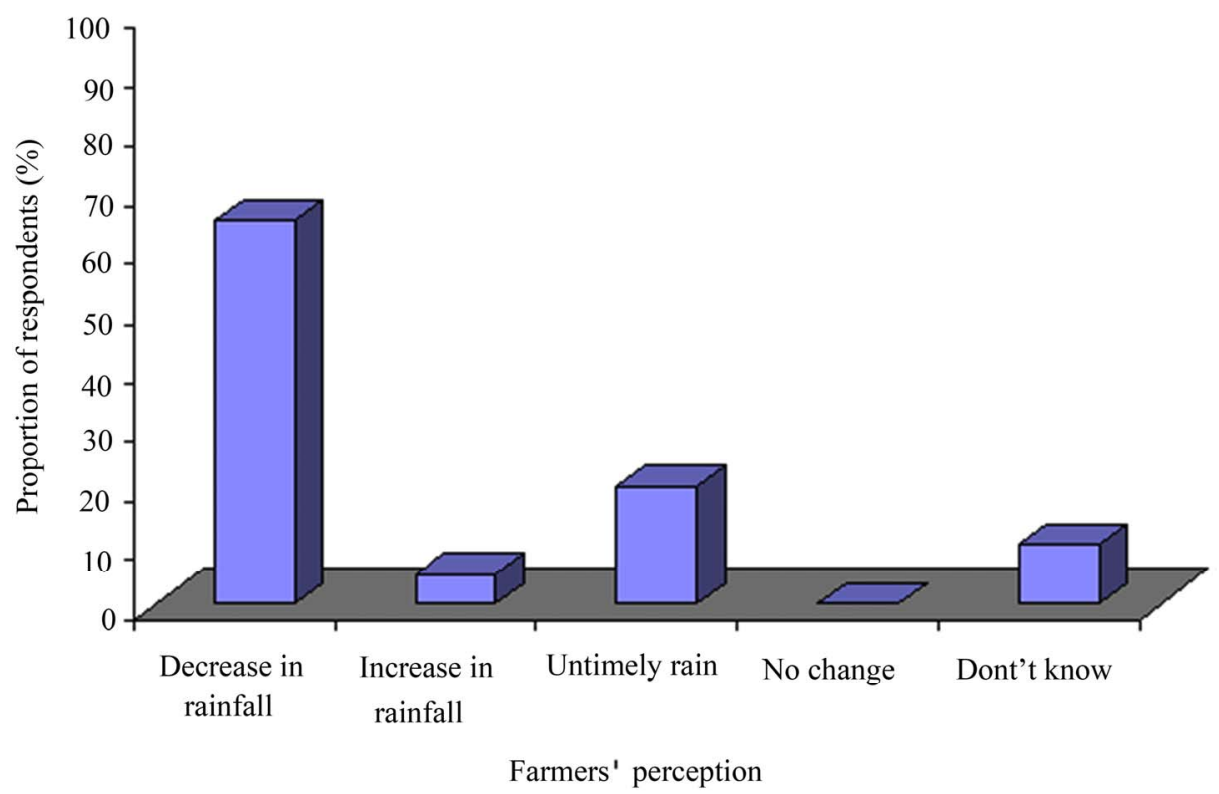

Figure 3. Farmers perception on the trend of rainfall change in Adiha.

participants, respectively. Hail storm and depletion of soil nutrients (coupled with soaring of fertilizer price) were ranked third by female and male respondents, respectively. This indicates that male and female farmers do not perceive hazards to equal degree.

\subsubsection{Vulnerable Groups of the Community}

Individuals or regions vulnerability depends on their adaptive capacity, sensitivity, and exposure to changing climatic patterns as explained by International Panel on Climate Change (IPCC). Ability of individuals to adjust to actual or expected climate impacts or to cope with the consequence of climate change varies to various degrees. The study revealed that children, elderly, disabled and poor farmers were rated as highly vulnerable groups of the society while landless farmers; female headed households and non irrigators were classified as medium vulnerable groups. Wealthy farmers who have good access to resources are less vulnerable to changing climate. Similar findings were reported by references $[2,3,9,10]$. Such understanding of the local dimensions of vulnerability is essential to develop appropriate adaptation strategies that will mitigate adverse consequences of climate change.

\subsection{Farmers' Knowledge and Perception on Climate and Weather Prediction and Forecast}

The livelihood of agrarian society affected heavily due 
Table 1. Hazard identification, scoring and ranking by Adiha communities.

\begin{tabular}{ccccccc}
\hline \multirow{2}{*}{ Hazards identified } & \multicolumn{2}{c}{ Male group } & & \multicolumn{2}{c}{ Female group } \\
\cline { 2 - 3 } \cline { 5 - 6 } \cline { 5 - 6 } \cline { 5 - 6 } Drought & Scores & Ranking & & Scores & Ranking \\
Untimely rain & 31 & 5 & 5 & & 16 & 2 \\
Hail storm & 3 & 4 & & 10 & 3 \\
Crop pests and diseases & 0 & - & & 2 & 6 \\
Depletion of soil fertility and soaring of fertilizer price & 13 & 3 & & 7 & 5 \\
Human disease & 26 & 2 & & 0 & - \\
Strong wind & 2 & 6 & & - & - \\
Lack of access to services & 1 & 7 & & 9 & 4 \\
\hline
\end{tabular}

to climate change. Farmers have indigenous traditional knowledge to predict and forecast the forthcoming conditions. Knowing such traditional knowledge provides an entry into understanding how a new type of climate information might be accepted [11]. Different signs and signals, of both environmental indicators and cultural beliefs were enumerated by the participants to predict the coming weather and climate conditions (Table 2) in the study area. The behavior of some animals like goats, insects and bee, is mentioned as the most common environmental indicators. Special voice of honey bees recognized as a special signal for forecasting immediate rainfall. Similar result was reported by [12]. The most common cultural environmental indicators were the beliefs that the color of the sky, amount and color of cloud gatherings, and wind directions will indicate whether the coming season will be wet or dry. Reddish sky color, sparse cloud on the sky and wind blowing from west to east are used to warn the dryness of the next cropping season.

These cultural environments have international acceptances as similar findings were reported by $[13,14]$. Environmental indicators and cultural beliefs are not always consistent, as they are part of each person's knowledge and experience and they tend to differ even within a village [12].

Some respondents, particularly elderly and religious fathers (priests), insisted to accept most of the environmental and cultural signs and signals as indicators for early warning system. The argument is that the knowledge of knowing future weather and climate condition is only given to God and anybody who makes an attempt to predict it is a magic. Their influence on others to tell what they fully know for weather prediction and forecast was significant. This in turn will have an impact on adjusting traditional practices to adapt to the ever changing climate. As such social milieu has power to prevent new ideas for change [15] there has to be an effort to influence the attitude and perception of such people for bet- terment of the society without ignoring the important positive role of existing social settings.

\subsection{Existing Climate Change Coping and Adaptation Strategies}

The farming industry has a long history of showing itself capable of responding to changing influences and of implementing adaptations and innovations as circumstances change. Research findings showed that there are a number of actions that individual farmer can implement, some of which are specific to particular enterprisees or land types and others have a more general application $[2,16,17]$. Farmers manage risks, including those related to climate, regularly as part of their everyday lives. To make sound decisions that minimize climate risks, such as adjusting time of planting to coincide with the onset of rains, and exploiting climate opportunities, farmers should access climate early warning information.

\subsubsection{Coping Strategies}

Farmers employ various coping strategies against climate risks. In the FDG, the coping strategies to protect against climate related hazards were discussed which include: food for work scheme, credit, petty businesses (such as firewood and charcoal selling), reduction of daily meal in amount and frequency to eat and migration. Similar coping strategies were reported from various studies conducted in different parts of the country $[2,18]$. There are common as well as different coping mechanisms for male and female respondents. Male respondents rated credit and migration as effective coping strategies while female respondents preferred petty work and daily meal reduction. However, female respondents argued that credit, food for work and migration are not the right type of coping strategies even though they are preference of male respondents. The difference in preference of the strategies by the two categories of respondents indicates variation in level of satisfaction (Figure 4) even though both use the strategy to escape the hazard. 
Table 2. Local techniques for Seasonal forecasting of rainfall occurrence and distribution in Adiha.

\begin{tabular}{|c|c|c|c|c|}
\hline $\begin{array}{l}\text { Signs and } \\
\text { signals }\end{array}$ & Detailed description of the indicator & $\begin{array}{l}\text { Time of year when indica- } \\
\text { tor is observed }\end{array}$ & Use of the indicator & $\begin{array}{l}\text { Reliability (high, } \\
\text { medium or low }\end{array}$ \\
\hline Sky color & $\begin{array}{l}\text { Reddish color of sky from the west } \\
\text { direction indicates shortage of rainfall } \\
\text { during the main crop growth period }\end{array}$ & during off season & $\begin{array}{l}\text { Determines the period of rainfall } \\
\text { onset and its distribution during } \\
\text { cropping season }\end{array}$ & Medium \\
\hline Clouds & $\begin{array}{l}\text { appearance of cloud on the sky indi- } \\
\text { cate probability of rainfall }\end{array}$ & $\begin{array}{l}\text { If appears from February } \\
\text { to March }\end{array}$ & $\begin{array}{l}\text { Good rainfall during the main } \\
\text { growing period }\end{array}$ & High \\
\hline Wind direction & $\begin{array}{l}\text { Warm wind from west to east direc- } \\
\text { tion }\end{array}$ & $\begin{array}{l}\text { near preparation of agri- } \\
\text { cultural lands }\end{array}$ & $\begin{array}{l}\text { Less or no rainfall and the sea- } \\
\text { son is dry }\end{array}$ & Medium \\
\hline $\begin{array}{l}\text { Animals } \\
\text { behavior }\end{array}$ & $\begin{array}{l}\text { Mating period of goats and special } \\
\text { peach of bee colonies sound }\end{array}$ & varies based on the animals & $\begin{array}{l}\text { It indicates as good rainy season } \\
\text { is coming and predict to have } \\
\text { good cropping season }\end{array}$ & Medium \\
\hline Plants & Early flowering of some plants & $\begin{array}{l}\text { In the middle of growth } \\
\text { period }\end{array}$ & $\begin{array}{l}\text { It indicates as rainfall is going to } \\
\text { cessation early }\end{array}$ & High \\
\hline
\end{tabular}

The level of satisfaction varies for different coping strategies. Male respondents are $100 \%$ satisfied with credit as a coping strategy while female respondents get full satisfaction from daily meal intake reducetion. Level of satisfaction gained (50\%) from labor and livestock selling is equal for both male and female respondents.

\subsubsection{Adaptation Strategies}

Adaptation is improved society's ability to cope with changes in climatic conditions across time scales, from short term (e.g. seasonal to annual) to the long term (e.g. decades to centuries) [2]. The IPCC [19] defines adaptive capacity as the ability of a system to adjust to climate change (including climate variability and extremes), to moderate potential damages, to take advantage of opportunities, or to cope with the consequences. The goal of an adaptation measure is to increase the capacity of a system to survive external shocks or change. The assessment of farm-level adaptation strategies is important to provide information that can be used to formulate policies that enhance adaptation as a tool for managing a variety of risks associated with climate change in agriculture. The FGD identified use of irrigation, planting early maturing and drought resistant crop varieties and soil and water conservation practices as the most important strategies used by the communities of the study area. Respondents, almost in all FGD, implied that changing of planting date and crop diversification are not commonly used in the area despite the effectiveness of the strategies in drought prone areas [2,20].

\section{DISCUSSION}

The rainfall of Adiha is getting more erratic both in distribution and amount. Combined with rising temperature, it is increasing the vulnerability of the community to climate hazards particularly drought. Change of climate with expected long-term changes in rainfall patterns and shifting temperature zones are expected to have significant negative effects on agriculture, food and water security and economic growth of the country [2, 21,22]. It was indicated that the intense and frequent drought that occurring has been negatively affecting agricultural production and food security of the community. Similar case was reported by reference [23]. This increase the vulnerability of individuals to climate related risks though the degree of vulnerability varies from individual to individual.

The difference in the vulnerability of farmers to climate related hazards is explained by the degree to which an individual in a community is affected by extreme weather conditions and associated climatic variations [8]. The degree of sensitivity of the community as a whole or part of the community depends on household wealth, access to and use of resources/technology, ages, gender and literacy rates. Farmers willing and capability to use different cultural and environmental signs and signals for weather prediction and forecast also determines their level of vulnerability to climate related hazards. Weather predication and forecast enables to devise appropriate coping and or adaptation mechanisms. The differential preference to coping strategies by male and female respondents indicates the importance of designing different approaches for male and female headed households in drought management and risk mitigation plan [2,24, 25]. Improving community's ability to cope with climatic conditions across time and space needs use of adaptive measures at different levels.

These adaptive measures adopted or developed based on the type and nature related risks. Changes in management activities, institutional settings and infrastructure that are enable effective response to the changes in climate that may occur. There is a need to apply options for diversified production systems and diversified livelihood options that can help vulnerable people cope with climate variability, more extreme events, increasing variability of precipitation, and the associated socioeconomic implications of these changes [26,27]. Therefore, 
innovative approaches that influence and improve the traditional practices such as inflexible sowing time and developing various adaptation strategies that enable the farmers survive extreme climatic events are important area of intervention. So far such skills and approaches are lacking in most developing countries particularly Africa [28,29]. Furthermore, climate information which feed into decision making is not suitable [28] for most resource poor farmers as they developed for developed countries.

\section{CONCLUSIONS AND POLICY IMPLICATIONS}

The farming community of Adiha noticed that their area is getting warmer and drier due to increased frequency of drought and changes in the timing of rains. Observed trends of temperature and precipitation support this perception. Hail storm, flooding, frequent droughts and changing precipitation patterns are among the major hazards related to climate change. Elderly, disabled, poor and landless farmers were classified as the most vulnerable to climate change. Female headed households are also more vulnerable than male headed ones. Level of vulnerability related to risk mitigation options the farmers use to cope or adapt to the hazard.

Farmers identified credit, food for work, labor and petty works, selling of livestock and reduction of daily meal intake as coping mechanisms to hazards particularly drought. They also practice some adaptation strategies even though only few crop types such as teff (Eragrostis tef), maize (Zea mays) and millets are grown in the area. This limits the chance of diversification despite the fact that diversification is among the basic adaptation options. Moreover, the cropping calendar is not flexible even though it ensures escaping of sensitive development stage of the crop of very harsh climatic conditions such as late season drought. The implication is that farmers need to adjust their management practices to ensure that they make efficient use of the limited rainfall for better food production.

Availability of climate information is a prerequisite for mitigating the adverse effect of climate variability, and capitalizing on beneficial effect, especially in Ethiopia where the livelihood and even lives of its people depend on natural climate. Hence, improving access to climate information is an important first step to improve the livelihood of people in such variable conditions. Complementary efforts must be made to ensure that the farmers understand the information and can modify their agricultural activities. Some part of the community, particularly, elderly and religious leaders, perception about traditional climate prediction and forecasts appears overly pessimistic. Therefore, efforts must be made to ensure that they understand the use of climate prediction and forecast as it will have significant impact on decision making of the community.

Addressing these issues to improve farmers' knowledge and perception on climate change, climate prediction and forecast and access them with wider choices adaptation options can significantly help them tailor their management practices to warmer and drier conditions. It would have a significant potential to increase and sustain their productivity even under changing climatic conditions. Examples of such policy measures include developing drought resistant crop varieties, improving the forecasting and dissemination of climate information, and promoting farm-level adaptation measures such as the use of irrigation technologies and adjusting planting dates. Such policies should treat the most vulnerable groups in a special way.

\section{ACKNOWLEDGEMENTS}

The author would like to thank Oxfam America for initiating and financing the study on Vulnerability and Capacity Assessment (VCA) in Adiha, which has been a valuable learning experience for all of us. I am grateful to the farmers of Adiha for tolerating endless questions and shared their indigenous knowledge.

\section{REFERENCES}

[1] Tarhule, A. and Lamb, P. (2003) Climate research and seasonal forecasting for West Africans: Perceptions, disseminations, and use? Bulletin of the American Meteorological Society, 84, 1741-1759. doi:10.1175/BAMS-84-12-1741

[2] Charles, N. and Rashid, H. (2007) Micro-level analysis of farmers' adaptation to climate change in Southern Africa. IFPRI Discussion Paper 00714, Washington DC, USA.

[3] Teshome, W., Peterson, N., Gebrekirstos, A. and Muniappan, K. (2008) Micro insurance demand assessment in AdiHa Tabia. Progress Report, Tigray Regional State, Ethiopia.

[4] World Bank (2006) Adaptation of water infrastructure investments to changing demands and climate variability: A systems approach. First National Expert and Stakeholder Workshop on Water Infrastructure Sustainability and Adaptation to Climate Change, US Environmental Protection Agency, Arlington, Virginia, 6-7 January 2008

[5] Getahun, T. (2003) The role of agricultural growth and poverty reduction in Ethiopia. Paper presented on the role of Agriculture International conference, Rome, 20-22 October 2003.

[6] Admassie, A. and Adenew, B. (2008) Stakeholder's perceptions of climate change and adaptation strategies in Ethiopia. Ethiopian Economic Association Research Report, Addis Ababa, Ethiopia. http://www.eeaecon.org

[7] International Food Policy Research Institute (IFPRI) (2003) Ending the Cycle of Famine in Ethiopia. Wash- 
ington DC.

[8] Temesgen, D., Hassan, R. and Ringler, C. (2008) Measuring Ethiopian farmers' vulnerability to climate change across regional states. IFPRI Discussion Paper No. 806, USA.

[9] Shewmake, S. (2008) Vulnerability and the impact of climate change in South Africa's limpopo river basin. International Food Policy Research Institute Discussion Paper No. 804, Washington DC, USA.

[10] DFID (Department for International Development) (2004) climate change in Africa. Key sheets on climate change and poverty. http://www.dfid.gov.uk

[11] Eakin, H. (1999) Seasonal climate forecasting and the relevance of local knowledge. Physical Geography, 20, 447-460.

[12] Ziervogel, G. (2001) Global science, local problems: Seasonal climate forecasting in a Basotho village, Southern Africa. Global Environment Change Research Community Workshop, Rio de Janeiro, 6-9 October 2001.

[13] Wilken, G. (1982) Agro-climatic hazard perception, prediction and risk-avoidance strategies in Lesotho, Department of Geography, Colorado State University, Colorado.

[14] Pepin, N. (1996) Indigenous knowledge concerning weather: The example of Lesotho. Weather, 51, 242248.

[15] Norman, W. (1982) The farming systems approach to research. Farming System Research Paper No.3. Kansas state university, USA.

[16] Loë de, R., Kreutzwiser, R. and Moraru, L. (2001) Adaptation option for the near term: Climate change and the Canadian water sector. Global Environmental Change, 11, 231-245. doi:10.1016/S0959-3780(00)00053-4

[17] Maddison, D. (2006) The perception of and adaptation to climate change in Africa. CEEP Discussion paper No.10, Center of Environmental Economics and Policy in Africa, University of Pretoria, Pretoria.

[18] DPPC (2000) Vulnerability profile: Strengthening emergency response abilities. Addis Ababa, Ethiopia.

[19] Intergovernmental Panel on Climate Change (IPCC) (2001) Climate change 2001: Impacts, adaptation, and vulnerability. Intergovernmental Panel on Climate Change. Cambridge University Press, Cambridge.

[20] Bradshaw, B., Dolan, H. and Smith, B. (2004) Farmlevel adaptation to climatic variability and change: Crop diversification in the canadian prairies. Climatic Change, 67, 119-141. doi:10.1007/s10584-004-0710-z

[21] Ringler, C. (2007) The impact of climate variability and climate change on water and food outcomes: A framework for analysis. In: van Bers, C., Petry, D. and PahlWostl, C., Eds., Global assessments: Bridging Scales and Linking to Policy, GWSP Issues in Global Water System Research, 2.

[22] NDMC (2006) National Drought Mitigation Center. Washington DC.

[23] Yesuf, M. and Bluffstone, R. (2007) Risk Aversion in low-income countries: Experimental evidence from Ethiopia. IFPRI Discussion Paper No. 715, Washington DC.

[24] Chambers, R. (1989) Editorial introduction: Vulnerability, coping and policy. IDS Discussion Paper No. 311, Institute of Development Studies, Brighton.

[25] Morris, M., Butterworth, J., Lamboll, R., Lazaro, E., Maganga, F. and Marsland, N. (2005) Understanding household coping strategies in semi-arid Tanzania, Department for International Development, UK.

[26] McKeon, G., Howden, S., Abel, N. and King, J. (1993) Climate change: adapting tropical and subtropical grasslands. Proceedings of the XVII International Grasslands Congress, Palmerston North, 1181-1190.

[27] Mortimer, M. and Manvel, C. (2006) Climate change: Enhancing adaptive capacity. Natural Resources Systems Program Briefing Note. http://www.nrsp.org.uk

[28] International Research Institute for Climate and Society (IRI) (2006) A Gap Analysis for the Implementation of the Global Climate Observing System Programme in Africa. IRI Technical Report 06-01, New York.

[29] Cooper, P., Dimes, J., Rao, K., Shiferaw, B. and Twomlow, S. (2008) Coping with better with current climatic variability in the rain-fed farming systems of sub-Saharan Africa: A dress rehearsal for adapting to future climate change. Agriculture, Ecosystems and Environment, 126, 24-35. doi:10.1016/j.agee.2008.01.007

[30] Glwadys, A. (2009) Understanding Farmers’ Perceptions and Adaptations to Climate Change and Variability. IFPRI Discussion Paper No. 00849, The Case of the Limpopo Basin, Pretoria.

[31] Kinuthia, J. (1997) Global Warming and climate impacts in Southern Africa: How might things change? http://www.brad.ac.uk 